\section{O que as teorias do reconhecimento têm a dizer sobre as manifestações de rua em 2013 no Brasil}

Recebido: 02.05.15

Aprovado: 26.07.16
Celi Regina Jardim Pinto*

Resumo: Este artigo tem como objetivo discutir as teorias do reconhecimento como instrumental para a análise das manifestações de rua ocorridas no Brasil em junho de 2013. Examina três autores: Nancy Fraser, Axel Honneth e Judith Butler, descrevendo os pontos centrais da teoria do reconhecimento de cada um deles, para assim apontar as possibilidades e os limites de sua aplicação no estudo em pauta. A hipótese que norteia o artigo é a seguinte: nas manifestações de rua de 2013, a ausência de sujeitos coletivos organizados caracterizou uma condição de dispersão e fragmentação, resultando em uma demanda por reconhecimento antipolítica e individualizada. Tendo em vista esse cenário, chegou-se à conclusão de que as teses de Judith Butler sobre reconhecimento foram as que se mostraram mais apropriadas à análise dos eventos.

Palavras-chave: teoria social, teorias do reconhecimento, pós-estruturalismo, Nancy Fraser, Axel Honneth, Judith Butler, manifestações de rua no Brasil em junho de 2013.

\section{$[\ldots]$}

Não sei por onde vou,

Não sei para onde vou

Sei que não vou por aí!

José Régio (1901-1969), "Poemas de Deus e do Diabo" (1925).

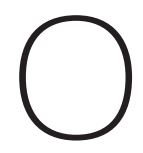

presente artigo tem como objetivo discutir as teses das teorias do reconhecimento ${ }^{1}$ com o intuito de avaliar a sua aplicação na análise das manifestações de rua ocorridas em junho de 2013 no Brasil. Parte-se da premissa de que a teoria dos movimentos sociais e a teoria da representação, vistas lato sensu no escopo da teoria democrática, não propiciam as melhores ferramentas para eventos como esses, que se apresentam como não políticos, antipolíticos, não organizados, espontâneos e individualizados.

Os manifestantes que tomaram as ruas naquele momento podem ser divididos grosso modo em dois grandes grupos: o primeiro, minoritário, composto de militantes de movimentos com histórias anteriores às manifestações; o segundo, majoritário, constituído por uma massa fragmentada de pessoas, que foram para as ruas sem qualquer organização anterior. O primeiro grupo tem sido vastamente trabalhado

\author{
* Doutora em \\ ciência política \\ pela University of \\ Essex (Inglaterra) \\ e professora da \\ Universidade Federal \\ do Rio Grande do Sul \\ (UFRGS). \\ <celirjp@gmail. \\ coms. \\ 1. Neste artigo, \\ serão empregadas \\ "teorias do \\ reconhecimento", no \\ plural, e não teoria \\ do reconhecimento, \\ por tratar de duas \\ perspectivas teóricas \\ distintas: a de \\ Nancy Fraser e a \\ de Axel Honneth, \\ representantes da \\ teoria social, e a \\ de Judith Butler, \\ pós-estruturalista \\ desconstrutivista.
}


2. Desde as últimas décadas do século $X X$, os movimentos sociais têm

ocupado a literatura sociológica nacional e internacional com estudos teóricos e empíricos, como os de Cohen e Arato (1994), Melucci (2001), Dagnino (2002), Gohn (1997; 2008), Costa (2002) e Scherer-Warren (1993).

3. Há exercícios de mapeamento das redes sociais que se interligaram em 2013 muito bem elaborados no site <www.labic.net>.

4. Dentre a grande produção acadêmica nacional e internacional acerca das teorias de Fraser e Honneth e a polêmica entre os dois, destacam-se textos mais atuais e alguns que se tornaram referência na área: Grueso (2012), Mendonça (2011a; 2011b), Garret (2010), Ibañez (2010), Pinto (2008), Matos (2004), Swanson (2005) e Zurn (2003).

5. Em seu site, o MPL assim se define: "o Movimento Passe Livre (MPL) é um movimento social autônomo, apartidário, horizontal e independente, que luta por um transporte público de verdade, gratuito, para o conjunto da população e fora da iniciativa privada". Quanto à sua história, afirma: na literatura sociológica²; o segundo, entretanto, é a novidade que os estudiosos têm dificuldade de entender para além das explicações que tratam de redes sociais $^{3}$. Ou seja, pouco se tem avançado sobre os estudos do fenômeno em si. É, pois, com foco nessa novidade que este artigo irá discutir as teorias do reconhecimento de Nancy Fraser, Axel Honneth e Judith Butler.

As diferentes propostas desses autores oferecem perspectivas promissoras para tal entendimento, com destaque para as teses de Butler, cujas ferramentas mostraram-se mais apropriadas para a análise dos eventos, visto que o momento do sujeito nas manifestações não corresponde aos sujeitos da teoria social, que buscam um porvir: a paridade de representação em Fraser e a "boa vida" em Honneth.

Inicialmente neste artigo se fará uma breve apresentação dos acontecimentos. Se passará a um recorrido das teses que embasaram a polêmica entre Fraser e Honneth, não se pretendendo, porém, repetir o encontrado, com bastante qualidade, na extensa produção sobre esses autores ${ }^{4}$. Assim, se retomará apenas os pontos que contribuem para desenvolver o argumento deste artigo, citando-se a conhecida polêmica na medida em que ela possa esclarecer as diferentes posições dos autores, principalmente no que se refere ao autorreconhecimento. Na sequência, se discutirá as teses de Butler sobre reconhecimento, comparadas, quando necessário, às de Fraser e Honneth, e se chegará, por fim, a algumas conclusões a respeito das teorias do reconhecimento aplicadas à análise das manifestações de rua ocorridas no Brasil em junho de 2013.

\section{Breve apresentação dos acontecimentos}

Em junho de 2013, a onda de manifestações que varreu o Brasil de norte a sul levou centenas de milhares de pessoas às ruas. A motivação inicial foi a mobilização do Movimento Passe Livre $(\mathrm{MPL})^{5}$ contra as propostas de aumento das tarifas de ônibus anunciadas por algumas prefeituras; as manifestações ocorreram agrupando um conjunto heterogêneo de pessoas, com demandas que variavam de questões muito específicas, como "contra a PEC 37 "6 e até mesmo "contra tudo que está aí". Entre os manifestantes havia uma minoria com militância política e adesão a movimentos sociais; outros, todavia, participavam pela primeira vez de um evento coletivo dessa natureza e tinham ido às ruas por curiosidade, convite de amigos ou colegas. Se há uma característica que primeiro qualifica essa multidão é a diversidade.

Em suma, nos dois grandes grupos identificados estavam, o primeiro - o Movimento Passe Livre - contava com militantes da esquerda radical, incluindo pequenos partidos, e os Black Blocs (BB) e suas derivações anarquistas; o segundo, agrupava 
a já citada majoritária massa disforme. No discurso de todos, há uma constante: o afastamento da política partidária e dos políticos. "Eles não nos representam" era um slogan encontrado em todos os grupos. O MPL, Os BB, os grupos anarquistas e de militantes da extrema esquerda defendiam a democracia direta e participativa, portanto não poderiam se sentir representados por aquilo que era justamente a motivação e causa do protesto. A grande maioria das pessoas que foram para as ruas com cartazes feitos à mão ${ }^{7}$ não se identificava, pelo menos publicamente, com partidos políticos e tinham uma relação escorregadia com a política, estavam nas ruas pelos motivos mais diversos, mas, contraditoriamente, em suas manifestações não aparecia uma decepção com a política partidária, mas a sua negação, o que tem um sentido bastante distinto; não havia uma luta por mudança na política, apenas o repetido bordão de que a política e os políticos não representavam os manifestantes. Queriam estar longe de qualquer solução política.

Este artigo, não é um estudo da ideologia política dos manifestantes, tampouco uma análise das eventuais intenções veladas da saída às ruas. A novidade do fenômeno é um grande grupo de pessoas terem saído às ruas afirmando que não gostavam de política, que eram contra os partidos, que não estavam envolvidos com a política ${ }^{8}$.

\section{Os reconhecimentos de Fraser e Honneth}

Nancy Fraser parte de uma crítica ao multiculturalismo, que, segundo ela, havia desprezado o lado econômico em proveito do cultural. Introduz a questão da redistribuição com estatuto diferenciado em relação ao reconhecimento, defendendo que ambos são uma questão de justiça e que não podem ser reduzidos a uma questão psicológica de autorreconhecimento e estima social, como acusa Honneth de fazê-lo. Afirma que:

Não se trata de ser tomado por uma identidade distorcida ou uma subjetividade enfraquecida como resultado de ser depreciado pelos outros. É, em vez disso, ser constituído por padrões institucionalizados de valores culturais de tal forma que impossibilite atuar com paridade na vida social (Fraser \& Honneth, 2003: 29)

Fraser abre com sua definição a possibilidade de reconhecimento sem autorreconhecimento, apoiando sua tese unicamente na questão de justiça. Tal possibilidade só existe porque Fraser separa reconhecimento de redistribuição, mesmo que admita que isso seja apenas uma distinção analítica. Pode-se concordar com a autora no que se refere à redistribuição, no sentido de que possa haver políticas de redistribuição anteriores a lutas por reconhecimento, mas é difícil entender como Fraser pensa que isso possa vir a se realizar, pois uma política redistributiva só se "o MPL foi batizado na Plenária Nacional pelo Passe Livre, em janeiro de 2005 em Porto Alegre, mas antes disso, há seis anos, já existia a Campanha pelo Passe Livre em Florianópolis. Fatos históricos importantes na origem e na atuação do MPL são a Revolta do Buzu (Salvador, 2003) e as Revoltas da Catraca (Florianópolis, 2004 e 2005). Em 2006 o MPL realizou seu II Encontro Nacional, com a participação de mais de dez cidades brasileiras, na Escola Nacional Florestan Fernandes, do MST [Movimento dos Trabalhadores Rurais Sem Terra]". Disponível em: <http://saopaulo. mpl.org.br> Acessado em: 10 Jun 2014.

6. A Proposta de Emenda Constitucional (PEC) 37 tirava do Ministério Público (MP) o direito de investigação. O MP fez grande campanha contra a sua aprovação. Nas ruas, apareceram cartazes, não artesanais mas todos iguais contra a PEC 37. Essa demanda e a forma como apareceu nas manifestações diferia muito do que acontecia de modo geral nas ruas, indicando um possível aparelhamento.

7. Havia cartazes contra a corrupção e contra todos os 
políticos: "somos contra tudo que está aí" era uma frase que se repetia em todas as cidades, "o povo unido não precisa de partido" era outra. A corrupção foi associada às obras para a Copa do Mundo de 2014 e para a Copa das Confederações, que acontecia na mesma época das manifestações. Havia também claras manifestações contra o governo da presidenta Dilma Rousseff em cartazes que diziam: "Dilma nós não acordamos fortes, nós somos fortes" ou "Sai Dilma, o povo é o dono do país". Estiveram muito presentes cartazes com trechos do hino nacional, como "verás que um filho teu não foge à luta" ou respondendo a frase "gigante pela própria natureza" com cartazes dizendo "o gigante acordou". Também havia manifestações claramente de direita como "Não à ditadura comunista no Brasil" ou "Chega de corrupção: intervenção militar já".

8. Ao observar o Brasil entre 1954 e 2013, é possível verificar um conjunto robusto de manifestações de rua, sempre com posições políticas muito bem definidas. As primeiras delas ocorreram dias 25 de agosto de 1954, quando grande quantidade de concretizará se houver um processo de reconhecimento, mesmo a posteriori, já que ninguém se autorreconhece como pobre; de nada adianta uma política de renda mínima, como o Bolsa Família, para usar um exemplo brasileiro, ou uma política de cotas para indígenas, se ninguém se reconhecer como tal.

Para fugir do que chama de psicologização, Fraser descarta o conceito de autorreconhecimento e, de certa forma, o de indivíduo, e adota duas unidades de análise e uma possibilidade de porvir. As unidades de análise são as classes e as identidades, o porvir seria a dissolução dessas classes e as diferenças contidas nas identidades, em uma proposta muito avizinhada à ideia original de comunismo em Marx. O problema, no entanto, se expressa porque Fraser trabalha sempre com sujeitos já sujeitados, numa perspectiva quase althusseriana (Althusser, 1971) do sempre já sujeito, não incorporando o processo de reconhecimento: independente de afro-brasileiros lutarem ou não por políticas de cotas, houve antes alguém que se identificou como negro, e esse processo de autorreconhecimento é parte essencial para que a luta aconteça e mesmo para que o aparato institucional tome medidas que promovam a justiça. Não haveria possibilidade de existir um discurso feminista se nenhuma mulher no mundo tivesse se sentido dominada e reconhecida como tal. Isso constitui uma impossibilidade lógica. E não haver luta contra a dominação não implica a inexistência de dominação, porém, para que se construa a noção de justiça como motor das demandas, devem estar presentes as condições de emergência da experiência da dominação. Em Fraser, a noção de justiça está amparada na contraposição a padrões culturais institucionalizados de injustiça, o que é correto; o problema está na não discussão das maneiras como os sujeitos se constituem dando forma a esses padrões e/ou se opondo a eles.

Aqui uma questão se impõe: quem se reconheceria como sendo objeto da violação da justiça? Dito de outra forma: quais as condições que necessitam ser dadas para que a luta por reconhecimento ou redistribuição aconteça? Fraser não se coloca essa indagação, uma vez que está implícita e explicitamente tratando de identidades pré-constituídas: classes, mulheres, negros em luta. São a eles que ela atribui as lutas por reconhecimento. O que não está presente na discussão de Fraser é que, para lutar por reconhecimento, deve haver um reconhecimento anterior. Fraser parte da crítica às identidades sem discutir como elas se formam. Não é por coincidência que o capítulo que abre a famosa polêmica com Honneth tem por título "Justiça social na era das políticas de identidade" (Fraser \& Honneth, 2003).

Ao identificar identidades como problema e não como um evento histórico, Fraser, em "Reconhecimento", no livro Justice interruptus: critical reflections on the "postsocialist" condition, publicado em 1997, expressava claramente seu desconforto 
com as políticas identitárias e lançava as noções de política de afirmação e política de transformação tanto para questões de distribuição como de reconhecimento, onde o momento ótimo das políticas de transformação levaria ao socialismo e à desconstrução das identidades. Dois problemas se apresentam nessa construção, o primeiro é que Fraser não tem uma teoria da revolução que dê suporte à sua proposta. No texto de 2003, aponta a estratégia de uma reforma não reformista e atribui a agência dessa reforma a "um bloco contra-hegemônico de movimentos sociais" (Fraser \& Honneth, 2003: 86) ${ }^{10}$. O segundo problema que a proposta de Fraser enfrenta é uma espécie de "novo mundo comunista", onde as desigualdades acabariam junto com as diferenças. Aqui seria necessário buscar suporte em uma teoria da democracia consistente, pois, de outra forma, se poderia estar descrevendo uma experiência totalitária ${ }^{11}$.

A teoria de Fraser poderia explicar o caso do Movimento Passe Livre como unidimensional. A gratuidade das passagens do transporte urbano é uma luta antiga, relacionada à dificuldade que muitos trabalhadores têm no Brasil de arcar com o alto custo do transporte diário. Quando, em junho de 2013, os representantes do grupo diziam que estavam lutando por 20 centavos, eles queriam reafirmar seu compromisso com essa questão econômica. Era uma luta por redistribuição, porém acrescida de uma perspectiva política que não se esgotava na redistribuição: o MPL também afirmava estar lutando por uma nova forma de participação política, através da participação direta dos cidadãos, o que implicaria reformas mais profundas.

Nas manifestações de junho de 2013, encontrava-se repetidamente marcada a ideia de distância entre quem está se manifestando e quem constitui o corpo da política institucional e, nesse sentido, Fraser tem pouco a contribuir. Esse afastamento talvez tenha sido a única questão que uniu todos os que estiveram nas ruas, mas o conteúdo do afastamento era muito diversificado. Mesmo quando uma demanda se repetia, ela aparecia dispersa entre os manifestantes. Não havia grupo lutando por uma demanda qualificada e com conteúdo específico ${ }^{12}$. Os grupos organizados, como o MPL e os BB tinham uma perspectiva política em sua participação no sentido de agirem, violentamente ou não, com um claro discurso antidemocracia representativa, afirmando que ela não funcionava como democracia, lutando, pois, por uma democracia direta, capaz de promover igualdade de participação ${ }^{13}$. A luta desses grupos é pelo reconhecimento de um novo tipo de cidadania, com a participação direta dos cidadãos nas decisões sobre a redistribuição.

A teoria de Fraser oferece algumas linhas de explicação para as lutas dos grupos organizados que estavam nas ruas para uma ação política, isto é, para lutar contra a democracia representativa, propondo, mesmo que muito vagamente, um novo pessoas saíram às ruas nas principais cidades brasileiras acusando a União Democrática Nacional (UDN), Lacerda e o imperialismo de serem responsáveis pelo suicídio de Getúlio. Nos primeiros meses de 1964, grandes manifestações ocorreram, principalmente no Rio de Janeiro, São Paulo e Belo Horizonte, contra o governo de João Goulart, acusado de comunista, a favor da família, de Deus e da propriedade. Em 1968, uma manifestação no Rio de Janeiro, conhecida como "a passeata dos 100 mil", fazia coro contra o governo militar, a censura e a tortura. Em 1983-1984, o Brasil se mobilizou novamente para pedir eleições diretas para presidente da República, na campanha Diretasjá!, contra o governo militar agonizante. Poder-se-ia listar um número bem maior de manifestações no período, todas marcadamente políticas em sua forma de expressão. Não há nenhum dificuldade para identificar cada uma delas no espectro político direita-esquerda. A distinção, em 2013, é a negação explicita de relações com a política e com suas ideologias, o que evidentemente não exclui a possibilidade de que essas pessoas 
tivessem posições políticas. Mas isto foge ao argumento deste artigo.

\section{Todas as citações} foram traduzidas pela autora, para uso exclusivo neste artigo.

10. Vale notar quase como curiosidade que Fraser explica o bloco contrahegemônico em uma nota de rodapé. Novamente aqui, como não tem uma teoria do conflito ou da revolução, ela constrói um discurso sem sujeito: "Existem duas formas de conceber tal bloco contra-hegemônico. Em um primeiro cenário (front unido), os movimentos componentes agrupam-se para dividir uma estratégia programática integrada unicamente para fazer frente à má distribuição e ao falso reconhecimento [...]. Em um segundo cenário (mais descentralizado), eles [os movimentos] remanescem relativamente separados e a coordenação é um contínuo processo de sintonia dentro de um fluxo conjunto de movimentos, cada um consciente e pensando bidimensionalmente em distribuição e reconhecimento (Fraser \& Honneth, 2003, nota 102: 109).

11. De forma alguma estou indicando que Fraser sugere ou aceitaria uma solução tipo de sociedade. Mas as teses de Fraser são limitadas para explicar o que houve de novo nas manifestações brasileiras, a massa de pessoas, centenas de milhares que foram às ruas não para buscar redistribuição ou lutar por participação paritária na política. Foram às ruas para dizer não à política, para negar a política. A frase repetida muitas vezes "O Brasil é meu partido" ou versos escolhidos do hino nacional afastavam essa massa da política institucional e mesmo de qualquer posicionamento político. Certamente eles estavam dizendo com seus cartazes feitos em casa alguma coisa, havia um reclamo por reconhecimento, mas parece que em Fraser não se obtém pistas para entender essa massa de não reconhecidos. A imensa maioria era composta de jovens universitários de classe média, mas não havia qualquer direcionamento que envolvesse a luta por algum direito dos jovens. Nunca o fato de serem jovens foi articulado em um discurso que lutasse por alguma forma de reconhecimento nos termos entendidos por Fraser ${ }^{14}$.

A teoria do reconhecimento de Fraser tem uma dimensão política, deve levar à paridade de participação, "uma paridade que se estabelece no direito à igualdade de cidadania" (Fraser \& Honneth, 2003: 29). A noção de paridade de participação sofre do mesmo problema da ideia de transformação através do reconhecimento, ou seja, como se chega a uma condição de igualdade? Se essa condição é necessária para a paridade, há necessidade de se dar conta das lutas anteriores que propiciarão as condições para acontecer a igualdade ${ }^{15}$. Da mesma forma que Fraser não explica como pensa a chegada ao socialismo, ela não consegue sair de uma armadilha por ela mesma colocada em relação à paridade participativa, que define como:

[...] de acordo com esta norma [participação paritária], justiça re-
quer arranjos sociais que permitam a todos (adultos) os membros
de uma sociedade interagirem uns com os outros como pares. Para
a paridade participativa ser possível, duas condições devem ser sa-
tisfeitas. A primeira: a distribuição dos recursos deve ser tal que
assegure independência e voz aos participantes. [...] A segunda
condição requer que padrões institucionalizados de valores cultu-
rais expressem igual respeito por todos os participantes e assegu-
re igual oportunidade para que adquiram estima social (Fraser \&
Honneth, 2003: 36). A primeira condição, ela enquadra em condições objetivas; a segunda, em intersubjetivas. A questão que a proposta de Fraser enseja é de como é possível chegar a preencher esses requisitos em uma sociedade em que a participação paritária não existe. Como essas condições seriam dadas fora da participação paritária? Por não possuir uma teoria do conflito (ou seria da revolução?), Fraser parece inverter o sentido do processo. A participação paritária deveria ser o resultado das lutas por 
redistribuição e reconhecimento e não o pré-requisito. Não há espaço para o encontro de forças antagônicas capazes de transformar, por um processo revolucionário (violento ou não), as condições anteriormente existentes. Salvo, o que é pouco provável, se Fraser constituísse como sujeito oculto uma vanguarda capaz de realizar a mudança em nome dos não paritários.

A teoria do reconhecimento de Honneth se estrutura a partir de três questões:

(i) a negação da dualidade redistribuição/reconhecimento;

(ii) a centralidade no indivíduo e na condição de desrespeito como motor da luta por reconhecimento;

(iii) a necessidade de uma teoria moral da "boa vida" sem a qual é impossível lutar por justiça.

Honneth define sua tese como

[...] uma tentativa de renovar os reclamos compreensivos da Teoria Crítica sob as condições presentes, faz melhor em orientar-se por um enquadramento categórico de uma teoria do reconhecimento suficientemente diferenciada, uma vez que estabelece ligação entre as causas sociais do disperso sentimento de injustiça e os objetivos normativos de movimentos emancipatórios (Fraser \& Honneth, 2003: 113).

Honneth não admite o dualismo, presente em Fraser. Afirma que não existe possibilidade de distinguir o material do simbólico. A polêmica entre os dois teóricos é de difícil solução. Fraser fala de hibridismo, advoga uma distinção analítica e tem dificuldade de identificar a luta meramente econômica. Em certo momento de sua argumentação, indica a luta de classes como uma luta econômica, mas, ao contrário das lutas por reconhecimento, não consegue chegar ao exemplo empírico dessa luta. Seria a luta sindical uma luta por redistribuição? O mesmo seria para a luta do Movimento Passe Livre? Em nenhum dos dois exemplos estamos frente à luta de classes, pelo menos no sentido dado a ela por Marx.

Mesmo admitindo que na luta sindical e na especificidade do MPL haja um momento de pura luta por redistribuição, ela nunca se expressa sozinha; no caso do Passe Livre, permeia a ideia de desrespeito aos direitos dos trabalhadores a um transporte público digno. Na luta sindical dos professores da rede pública brasileira por melhores salários e melhores condições de trabalho, por exemplo, existe, no discurso em tempo de greve, o princípio do desrespeito ao trabalho de professor, que começa nas instâncias de governo e acaba dentro da sala de aula. de tipo totalitário, apenas aponto a falta de saídas políticas decorrentes de sua proposta.

12. Marcos Melo e Carlos Pereira (2013: 165), comentando as manifestações de 2013 no Brasil, são enfáticos em mostrar a dispersão de possíveis demandas: "Que fatores explicam a onda de protestos de junho de 2013 em todo o país, que em uma primeira vista poderiam sugerir níveis significantes de instituições insatisfatórias e com mal funcionamento? Diferente de muitos especialistas, nós defendemos que o problema não é de falha do desenho institucional ou instituições políticas disfuncionais.

A recente onda de protestos e espalhadas manifestações no país não resultam nem de democratização insuficiente nem da falta de representação política, no sentido que nenhum interesse político está fora ou não é representado no jogo político".

13. Nossa sociedade é permeada por símbolos. Participar dos Black Blocs é usá-los para quebrar preconceitos, não somente o alvo atacado, mas a ideia de vandalismo. Não há violência, mas performance. "Eu não me sinto 
representado pelos partidos." "E não sou a favor da democracia representativa, mas da democracia direta." "Não é depredação pelo simples prazer de quebrar coisas, mas atacar símbolos que estão representados lá" (Roberto, nome fictício em entrevista à revista Carta Capital, em 5 Ago. 2013).

14. O Ibope fez uma pesquisa nacional, no dia 20 de junho de 2013, dia de pico das manifestações, e chegou a dados muito significativos sobre quem estava nas ruas. Dos manifestantes, $63 \%$ tinham entre 14 e 29 anos; $92 \%$ tinham o colegial completo, estavam na universidade ou já a haviam concluído; $72 \%$ trabalhavam e $52 \%$ estudavam; $56 \%$ tinham renda familiar entre 2 e 10 salários mínimos e $23 \%$, renda familiar acima de 10 salários mínimos. Disponível em: <g1.globo.com>. Acessado em: 18 Set. 2013.

15. Este tema foi discutido por mim em artigo anterior. Ver Pinto (2008).

16. "O 'amor' (a ideia central das relações íntimas), a igualdade de princípios (as normas das relações legais) e o princípio de realização (o padrão da hierarquia social) representam perspectivas normativas acerca
As teses de Honneth parecem muito apropriadas para mostrar que, nas lutas contemporâneas (e talvez não somente nelas), não há um abandono da questão da redistribuição, que, de forma diversa, sempre estiveram ancoradas nas lutas por reconhecimento.

Honneth articula diretamente o reconhecimento ao sentimento de desrespeito vivenciado por classes, grupos e indivíduos. O reconhecimento, para o sociólogo alemão, passa por três esferas: a do amor, a da lei e a da estima ${ }^{16}$. A primeira está no campo das relações pessoais; a segunda, da igualdade de todos os cidadãos perante a lei; e a terceira busca o reconhecimento que anule a hierarquia da escala de valores da sociedade. Com a terceira esfera, ele pretende enfrentar o que indica como uma das bases do capitalismo, "onde, à exceção da burguesia, as pessoas só têm reconhecimento pelo que conseguem alcançar como cidadãos produtivos". Para o autor, o indivíduo e sua autonomia são essenciais para que haja uma luta pelo que chama de "boa vida". O reconhecimento nessas três esferas é entendido por ele como "a possibilidade do crescente assegurar da singularidade da própria personalidade em um contexto de aprovação social" (Fraser \& Honneth, 2003: 143).

Fraser critica fortemente Honneth por reduzir todas as lutas em luta por reconhecimento, perdendo, com isso, a especificidade do conceito. E afirma que, para o sociólogo alemão, há um reconhecimento pré-político, que assim descreve:

Longe de constituir genuinamente um ponto de referência iminentemente empírico, sua invocação do sofrimento pré-político serve como pretexto para introduzir uma psicologia moral quase transcendental, que sustenta estabelecer uma vez por todas que o reconhecimento é sempre e em qualquer lugar a única e suficiente categoria da moralidade (Fraser \& Honneth, 2003: 207).

Ricardo Mendonça (2012: 132) percebe com muita precisão a fragilidade da crítica à dimensão psicológica presente nas teses de Honneth: "Do contrário, a própria formação do self e as relações que a atravessam passam a merecer atenção".

A preocupação empírica pressuposta neste artigo demanda especial cuidado com a questão do indivíduo, muitas vezes marcado negativamente na teoria social como uma invenção iluminista, recriado constantemente pelo capitalismo como cidadão, consumidor, contribuinte, corpo a ser dominando. Pensá-lo como ente desprovido de classe, gênero, sexo, etnia, história seria um erro primário, mas apagá-lo, imergindo-o em uma categoria de natureza coletiva, seria um erro da mesma sorte. As teses de Honneth parecem contribuir para trazer esse indivíduo à cena, ao mesmo 
tempo autônomo e historicizado. A categoria de autorreconhecimento possibilita identificar a massa de injustiçados fora dos movimentos sociais e das identidades forjadas por estes, pois, segundo Honneth, já teriam um nível de reconhecimento na própria condição de pertencer ou estar incluído no movimento social. Tal perspectiva abre possibilidades de análise dessas multidões que vão às ruas, sem nomes próprios atribuídos pelos movimentos sociais. Honneth dá especial atenção à questão quando afirma em relação aos últimos:

O erro reside na tácita premissa inicial de que "movimentos sociais" podem proporcionar à teoria social crítica um tipo de fio condutor, empiricamente visível, para diagnosticar normativamente áreas de problemas relevantes. O que esse procedimento deixa de fora é o fato de que a designação oficial de "movimento social" é em si o resultado de uma luta subterrânea por reconhecimento, conduzida por grupos ou pessoas afetados por sofrimento social que fazem o público perceber e registrar seus problemas (Fraser \& Honneth, 2003: 120).

A última questão fundamental para Honneth é a reafirmação da própria teoria social, no sentido de seu compromisso moral com a libertação. Há uma perspectiva moral quando ele associa reconhecimento a um sinal positivo essencial, chegando a falar de um "interesse quase transcendental da raça humana que objetiva desmantelar assimetrias sociais e exclusões" (Fraser \& Honneth, 2003: 174). Para isso, retoma seus três princípios de reconhecimento - o amor, as normas legais e o princípio das realizações -, que promoveriam uma existência de indivíduos interagindo em um mundo de integração social.

A teoria do reconhecimento desenvolvida por Honneth pode ser vista em relação à de Fraser de duas formas: Fraser postula um problema eminentemente político em seu esforço de trazer à superfície o tema da redistribuição e da paridade de participação; Honneth trata de construir uma teoria complexa de reconhecimento, a partir de um princípio moral de justiça. Uma segunda distinção entre as duas teses refere-se ao fato de que Honneth representa um avanço em uma espécie de teoria não declarada do sujeito, não presente em Fraser. Essa teoria não declarada do sujeito, através do autorreconhecimento em três esferas distintas, abre perspectivas para se examinar a fragmentação do sujeito, da qual são bons exemplos os manifestantes nas ruas das cidades brasileiras em 2013. É bastante razoável afirmar que, se algo havia naquelas manifestações, era a luta por reconhecimento, não obstante muito peculiar, pois buscava um reconhecimento como indivíduos não políticos, não identitários e, portanto, reivindicando uma espécie de pureza, se autoidentificando como não tocados pelo poder ou pela corrupção.

das quais os sujeitos podem razoavelmente argumentar que as formas existentes de reconhecimento são inadequadas ou insuficientes e necessitam ser expandidas" (Fraser \& Honneth, 2003: 143). 
Uma contribuição interessante a essa questão é o argumento de Jacinta Swanson, que, ao criticar o mecanicismo de Iris Young e Nancy Fraser em atribuírem posturas determinadas aos oprimidos, afirma:

[...] aqueles que são oprimidos interpretam suas opressões em uma larga variedade de formas: podem negar que são oprimidos, podem justificar suas opressões como natural ou como socialmente benéficas, podem ativamente resistirem às suas opressões (embora essa resistência também possa vir de variadas formas) etc. Por essas duas razões, os objetivos políticos e as identidades de membros de um mesmo grupo são plausíveis, podendo variar amplamente (Swanson, 2005: 106).

Em relação a Swanson, é possível avançar mais ainda, admitindo-se que a luta por reconhecimento não é obrigatoriamente contra a opressão; o sentimento de desrespeito pode mobilizar grupos dominantes em contextos de ameaça de perda de poder. Nessa direção, Veit Bader (2007), em um texto bastante crítico à teoria do reconhecimento de Honneth, levanta uma questão fundamental para dissociar o elemento moral, ou mesmo de justiça, da teoria do reconhecimento. Bader comenta:

[...] mas as reclamações de falso reconhecimento são particularmente difíceis de avaliar: é muito difícil traçar uma linha entre queixas legítimas e ilegítimas porque elas são fortemente moldadas por assimetrias de poder. Essa é a causa por que todos os antigos donos de escravos, altas castas, estamentos e classes - em suma, todos os positivamente privilegiados - queixam-se de ser moralmente injuriados, particularmente por não serem tratados com "o devido respeito", e porque demandas de identidade, autenticidade e integridade são tão maleáveis e estrategicamente manipuladas (Bader, 2007: 259).

A crítica de Bader abre uma interessante perspectiva que, incorporando a teoria de reconhecimento de Honneth e suas três esferas, permite pensar em lutas por reconhecimento que não caminhem na direção da justiça ou da moralmente definida "vida boa", mas, ao contrário, lutas que reforcem os privilégios algumas vezes ameaçados. Nesse sentido, pode-se pensar nas múltiplas lutas por reconhecimento presentes nas manifestações de 2013, que caminhavam até mesmo em sentido contrário umas das outras. Havia os que lutavam para ser reconhecidos como cidadãos com direitos sociais garantidos e, no polo oposto, os que lutavam para ser reconhecidos como indivíduos prejudicados pelo alargamento de direitos sociais. 


\section{O reconhecimento no desvio - Judith Butler}

Quais os avanços manifestados por Judith Butler em relação a Nancy Fraser e Axel Honneth, como possibilidade de explicação para as manifestações de rua de 2013 ? Em Butler, pode-se perceber e incluir como variável importante na explicação dos eventos a condição de dispersão. A ideia de que "eu não estou aqui em nome de ninguém, não estou representando nenhum partido, nenhum movimento, estou aqui apenas em meu próprio nome" foi o que prevaleceu nesses acontecimentos. Esse "sujeito indivíduo" clama por reconhecimento de sua individualidade, de sua condição de opositor, seja ao Estado, ao governo de plantão, ao capitalismo, aos impostos que paga, aos programas de renda mínima e de saúde do governo etc. É um sujeito que se constitui fora do âmbito político em sua maioria, não propõe, não defende ideias, não faz diferença se é de esquerda ou direita - fato este apenas perceptível quando se observa contra o que grita nas ruas. Manifesta-se contra os políticos, dizendo que eles não o representam, mas não pede outra forma de representação (fora os grupos organizados e minoritários, como os BB, que defendem uma democracia de direita, mas sem nenhuma liderança entre as massas das ruas). Não é um sujeito pré-político, mas antipolítico.

As interpretações acadêmicas ou advindas de políticos acerca das manifestações que ocorreram ao redor do mundo em 2011 e 2013 parecem bastante distanciadas do sentido que tiveram para quem estava nas ruas. A pouca ou nenhuma repercussão das propostas da presidenta Dilma ${ }^{17}$ ou o exagerado entusiasmo de acadêmicos como Manuel Castells ${ }^{18}$ com os indignados europeus, indicam que tanto a chefe de Estado como o sociólogo falavam de um sujeito que não era aquele presente nas manifestações.

Butler (2012), em sua crítica à noção de identidade de gênero, traz para a discussão pontos que possibilitam uma perspectiva diferenciada de análise dessa questão. Nas primeiras páginas de seu livro Problemas de gênero, referindo-se às mulheres, afirma:

Se alguém "é uma mulher", isso certamente não é tudo que esse alguém é; o termo não logra ser exaustivo, não porque os traços pré-definidos de gênero da "pessoa" transcendam a parafernália específica de seu gênero, mas porque o gênero nem sempre se constituiu de maneira coerente ou consistente nos diferentes contextos históricos, e porque o gênero estabelece interseções com modalidades raciais, classistas, étnicas, sexuais e regionais de identidades discursivamente constituídas. Resulta que se tornou impossível separar a noção de "gênero" das interseções políticas e culturais em que invariavelmente ela é produzida e mantida (Butler, 2012: 20).
17. Entre os dias 20 e 24 de junho de 2013, a presidenta Dilma foi duas vezes à televisão para falar em cadeia nacional sobre as manifestações. No dia 21 de julho, ela foi a televisão pela primeira vez, quando as manifestações ainda ocupavam as ruas. Nessa oportunidade, seu discurso enfatizou três pontos: o direito das pessoas de se manifestarem; a necessidade da manutenção da ordem e da não aceitação de qualquer tipo de violência; as ações que o governo tomaria em relação ao transporte e à reforma política. A reforma política surgiu no discurso presidencial como central, em que pese não ter sido mencionada nas ruas, mas estava muito claro que havia um grande distanciamento entre os cidadãos e a política institucional nas repetidas declarações dos manifestantes, de que não tinham nada a ver com os partidos e que nenhum político os representavam. A resposta do governo foi reforçar a importância da política. Tanto que a presidenta afirmou: "quero contribuir para a construção de uma ampla e profunda reforma política, que amplie a participação popular. É um equívoco achar que qualquer país 
possa prescindir de partidos e, sobretudo, do voto popular, base de qualquer processo democrático. Temos de fazer um esforço para que o cidadão tenha mecanismos de controle mais abrangentes sobre os seus representantes". Disponível em:

<http://www2.

planalto.gov.br/ imprensa/discursos>. Acessado em: 20 Nov. 2013.

18. Castells encontra nos movimentos de 2011 a semente de um novo projeto político de democracia participativa e de empoderamento popular. Reconhece que são movimentos com demandas muito variadas e, por isso, barram a possibilidade de construir um foco de luta, mesmo assim afirma que são movimentos fundamentalmente políticos: "Em particular quando eles propõem e diretamente praticam democracia deliberativa baseada em uma democracia de rede" (Castells, 2012: 222).

19. Butler, e outros pós-estruturalistas (às vezes também chamados de pósmodernos, quase como uma ofensa) têm sido acusados de desconstrutivistas, psicologizantes e arautos da fragmentação. Há aqueles que veem a fragmentação como ponto de partida
Na assertiva de Butler, gênero pode ser substituído por incontáveis outros sujeitos da modernidade, o que possibilita trazer para a discussão o distanciamento entre o sujeito nominado por outrem e o sujeito concreto em sua vida cotidiana. A complexidade dos sujeitos concretos atuais escorre entre os dedos daqueles que querem aprisionar suas identidades. Uma crítica feita a Butler, e aos desconstrutivistas em geral, é de que não há como não admitir momentos de articulação de identidades, não é possível trabalhar apenas com a fragmentação. Butler responde a essa crítica perguntando: "A unidade é necessária para a ação política?", e acrescenta:

\begin{abstract}
Certas formas aceitas de fragmentação podem facilitar a ação, e isso exatamente porque a "unidade" da categoria mulher não é nem pressuposta nem desejada. Não implicaria a "unidade" uma norma excludente de solidariedade no âmbito da identidade, excluindo a possibilidade de um conjunto de ações que rompesse as próprias fronteiras dos conceitos de identidade, ou que buscasse precisamente efetuar essa ruptura como um objetivo político explícito? (Butler, 2012: 36) ${ }^{19}$.
\end{abstract}

Butler trata de desconstruir identidades, mas não acolhe a ideia de uma fragmentação essencial, ao contrário, defende a possibilidade de uma coalizão aberta, a qual

portanto, afirmaria identidades alternativamente instituídas e abandonadas, segundo as propostas em curso; tratar-se-á de uma assembleia que permita múltiplas convergências e divergências, sem obediência a um télos normativo e definidor (Butler, 2012: 37) ${ }^{20}$.

Quando Butler se refere a "identidades instituídas e abandonadas", isso demonstra que ela prevê sua existência, mas nega, ao mesmo tempo, certo essencialismo, isto é, a necessidade dessa existência. As diversas leituras que podem ser feitas das manifestações de 2013 no Brasil estão muito relacionadas à pluralidade e à fragmentação de demandas por reconhecimento que estiveram nas ruas. A realidade desses eventos radicaliza a posição de Butler, pois muito pouco provável seria haver coalizão, em uma mesma manifestação, entre usuários do Sistema Único de Saúde (SUS) demandando por mais serviços públicos de qualidade e médicos lutando contra as políticas de deselitização da medicina.

Na introdução à coletânea The question of gender-Joan W. Scott's critical feminism, de 2011, Butler, ao abordar a crítica de Scott ao conceito de classe trabalhadora em Thompson, levanta uma questão já muito debatida acerca de classe, mas que provoca reações muito acirradas quando o objeto são outras identidades: 
Nós temos de perguntar isto? Através de que meios a classe trabaIhadora emerge como categoria histórica? Se a classe trabalhadora é em si uma emergência histórica específica, e sua chegada como categoria histórica é a consequência de certa mudança no nosso entendimento da história, então a emergência da categoria (ou conceito) é em si uma mudança histórica digna de nota (Butler, 2011: 17).

Desse entendimento deriva sua noção de agência, que emergiria do processo histórico sem determinações estruturais, o que lhe permite apontar para a historicidade de termos como gênero, trabalho e desigualdade. As teses de Butler promovem maior acuidade para se perceber que há momentos na história em que são visíveis sujeitos coletivos em confronto, em luta por direitos, por transformações; mas como eles são históricos, nada indica que não haja momentos de muita fragmentação, onde é impossível a constituição de coletividades, ou são momentos de sujeitos coletivos em crise.

As manifestações de 2013 no Brasil evidenciaram um momento de fragmentação das identidades, nenhuma identidade anteriormente construída teve condições de construir um discurso capaz de representar quem pretendia representar ou qualquer outra identidade. Quando os manifestantes diziam "ninguém me representa" estavam também falando do manifestante ao lado. As atitudes violentas contra a presença de bandeiras de partidos políticos nessas manifestações parecem revelar o temor por parte de alguns manifestantes de serem confundidos com os que se sentiam representados por aquelas bandeiras.

Dessa forma se conclui que não havia uma demanda por reconhecimento político, mas basicamente uma luta por reconhecimento da existência do sujeito que se queria fora da política. Esses manifestantes deixam Fraser e Honneth órfãos, pois, ao mesmo tempo que se pode identificar neles uma luta por reconhecimento, até mesmo mais próximo do que Honneth propõe, não há qualquer tipo de articulação que possibilite ver a ideia de força de justiça ou de "boa vida". Em suma, não há um porvir pelo qual se luta. Trata-se da luta pelo reconhecimento do outro (o político) como negação, de si como a própria negação do político, a negação da ação pública, e uma espécie de privatização do espaço público, diferente, por exemplo, de indivíduos que participam de um comício durante uma campanha eleitoral, quando se está lá como militante, como eleitor, como sujeito de uma visão de mundo. Esse não foi o caso do Junho de 2013, em que a luta era pelo reconhecimento do indivíduo, particularizado, com interesses pessoais, posições pessoais; negava o interesse público, a solução coletiva, que viesse de um partido ou de uma visão de mundo articulada. e de chegada.

Representam o outro

lado da mesma

moeda das teorias

da totalidade.

Entretanto, a

percepção de

que totalidades

e identidades -

sejam de classe

ou gênero, etnia,

raça, sexualidade

- estão sofrendo

um processo de

esgotamento, pelas

formas que as lutas

tomaram ou pelo

atual momento

do capitalismo

globalizado e

imperialista, é um

achado fundamental

para se entender as

novas configurações

das lutas. Isso não

implica a priori que

novas ou velhas

identidades não

se articulem no

decorrer das lutas.

Nesse sentido, as

teses de Ernesto

Laclau podem

ser consideradas

precursoras desse

posicionamento

teórico: "A

impossibilidade de

uma fixação última

de significado implica

que tem de haver

fixações parciais -

de outra forma, as

reais flutuações de

diferenças seriam

impossíveis. Mesmo para diferir, subverter um significado, tem de haver um significado" (Laclau \& Mouffe, 1985: 112).

20. Iris Young (1989:

268), no artigo

"A critique of the ideal of universal citizenship" defende a ideia de uma coalizão aberta, arco-íris: "Na forma tradicional de coalizão, grupos 
diversos trabalham juntos para fins que eles concordam ou que thes afetam de forma similar, e eles geralmente concordam que essas diferenças de perspectivas, interesses, ou opinião entre eles, não aflorarão nas manifestações públicas e nas ações da coalizão. $\mathrm{Na}$ coalizão arco-íris, em contraste, cada um dos grupos constituintes afirma a presença dos outros e afirma a especificidade de sua experiência e perspectiva nas questões sociais". A coalizão proposta por Young mantém a identidade de grupos, mas já contém uma clara abertura para a incompletude ou seja, para o espaço do outro, que não permite ser nenhum dos grupos completamente fechados.
Sem entrar na complexa discussão sobre as possíveis relações entre o Junho de 2013 e os movimentos de 2011 e 2012 na Europa e na chamada Primavera Árabe, cabe, neste momento, apenas para elucidação do argumento que está se desenvolvendo, citar que há uma distinção interessante a ser observada entre eles. Nas manifestações europeias, e mesmo as acontecidas na África e Ásia, houve ocupação do espaço das praças e a construção de um Eu coletivo, de uma coalizão do tipo indicado por Butler. A relação entre os Eus foi-se então modificando naquele tempo/ espaço, constituindo-se em nova dinâmica. O jovem que chegou sozinho na praça e se incorporou ao movimento (e são inúmeros os relatos), possivelmente voltou sozinho para casa após alguns dias de ocupação, mas o retorno ao privado é o retorno do Eu modificado, porque, seguindo o pensamento de Butler (2004: 19), o retorno ao privado nessas circunstâncias seria vivido como perda, como luto, que resulta em um ganho do Eu renovado.

No caso brasileiro, não houve o momento da ocupação espacial e temporal que possibilitasse a construção de um Eu coletivo, houve a pulverização de Eus buscando o reconhecimento individual da negação do político. Daí haver uma barreira para pensar ou se reconhecer no coletivo. A volta à casa após poucas horas de manifestação "solitária" não é vivenciada como perda, como luto capaz de transformar cada Eu.

No encalço de Hegel, Butler chama a atenção para o fato de que, ao reconhecermos, estamos compelidos a ser reconhecidos, o que coloca as identidades em relação e não como identidades separadas. Para a filósofa, reconhecer a humanidade do outro modifica nossa humanidade. Quando reconhecemos a vulnerabilidade do outro, isto é, sua humanidade, estamos reconhecendo a nossa própria vulnerabilidade como humanos.

Reconhecer ou lutar por reconhecimento é um ato de transformar-se. Uma vez que sou reconhecido, não sou mais o Eu anterior, pois sou o Eu reconhecido. Da mesma forma acontece com quem reconhece. Esse entendimento do reconhecimento é muito distinto das teses de Fraser e Honneth e acrescenta uma questão não discutida por eles, que se poderia chamar de uma dialética do reconhecimento, a qual envolve a transformação do outro que reconhece, que pode se autorreconhecer como ameaçado pela necessidade de reconhecer aquele que interrompe sua ilusão de completude. Quando uma classe, ou grupo, que se sente plenamente segura em seus privilégios é ameaçada pela necessidade (criada pelas condições históricas e de lutas) de reconhecimento do outro, há a possibilidade de reações conservadoras, racistas, homofóbicas etc. Quando não mais só os brancos podem chegar às universidades, ou quando não só as famílias heterossexuais são reconhecidas legalmente, 
brancos heterossexuais tendem a reagir negativamente. Tais circunstâncias dão a medida da complexidade dos processos de reconhecimento.

Para os propósitos deste artigo, não avançarei na questão filosófico-psicanalítica que embasa a questão da vulnerabilidade na obra de Butler, tomarei outro rumo e me fixarei no seu último livro, de 2013, escrito em forma de diálogo com Athena Athanasiou, onde as duas discutem a noção de reconhecimento incorporando as dimensões política e de poder. É mister chamar a atenção para o fato de que estas são dimensões fundamentais, ausentes das teses de Fraser e Honneth, pois, na medida em que pensam reconhecimento como libertação, a dimensão das relações de poder só faria sentido no não reconhecimento ou no falso reconhecimento.

Athanasiou introduz a noção de astúcia do reconhecimento no que concerne ao reconhecimento legal, institucional e discursivo, que reproduz as desigualdades dos regimes nacionais liberais (Butler \& Athanasiou, 2013: 75). Sua questão é de como se sobrevive a esse tipo de reconhecimento desafiando-o ao mesmo tempo. Butler responde com a questão levantada por Gayatri Spivak sobre "coisas que nós não podemos não querer". O exemplo que oferece é o da mulher que recorre ao aparato legal quando é estuprada. Independentemente de ser o Estado liberal e até sexista, da existência de exploração da mulher no trabalho etc., as mulheres não podem não aceitar uma lei, desse mesmo Estado, que Ihes protege contra o estupro.

Segundo Butler, isso nos coloca frente ao que não podemos não querer, pois a lei que reconhece o crime de estupro é fundamental. O diálogo entre Butler e Athanasiou aborda questões da luta política que abrem possibilidades de melhor entendimento das manifestações de 2013. A primeira questão se refere à presença do outro, aquele que reconhece. Não se trata de uma perspectiva voluntarista; o reconhecimento é resultado de luta.

É razoável pensar que a luta por reconhecimento é um jogo de soma zero, onde $\mathrm{o}$ ato de reconhecer torna o reconhecedor menos poderoso e o reconhecido empoderado. Quando milhares de pessoas saem às ruas em manifestações, fecham avenidas, transformam o cotidiano das grandes cidades, elas provocam um tipo de reconhecimento (não necessariamente o que buscam) por parte do Estado (aparato policial, Poder Executivo).

Athanasiou, mesmo concordando com Butler, pergunta:

Como a teoria sobre a luta por reconhecimento necessita ser reformulada para envolver as relações de poder que equalizam elegibili- 
dade por reconhecimento com as normas que determinam a viabilidade da subjetividade humana? (Butler \& Athanasiou, 2013: 78).

Argumenta que as teorias do reconhecimento partem de um agente preexistente, que luta por reconhecimento, não levando em conta as relações de poder que estão envolvidas nesses sujeitos. Seu questionamento é no sentido de se perguntar como o sujeito que necessita aceitar o que não pode deixar de aceitar, isto é, o ordenamento liberal da sociedade, pode se manter aberto para futuras rearticulações. Athanasiou radicaliza uma questão nunca aprofundada por Fraser ou Honneth, que é a do enfrentamento com o ordenamento do poder da sociedade. Na verdade, a antropóloga grega está se perguntando como se sai de um momento para o outro. E segue seu raciocínio agregando outra questão ausente nos debates sobre reconhecimento, que é a presença do Estado como o grande ente reconhecedor. Novamente se pergunta como o novo acontece frente a este poder.

Nas manifestações de 2013, no Brasil, havia uma polícia militarizada, violenta e mal treinada, para atuar durante as grandes concentrações, o que resultou em um confronto entre a força policial e alguns manifestantes. Nenhum lado encontrou no outro o limite ("o que não podemos não aceitar"). Esses manifestantes foram "reconhecidos" pela mídia e pelas autoridades estatais como vândalos, em contraposição a manifestantes legítimos, que desapareciam quando a violência começava, porque estava apenas querendo que fosse reconhecido o seu direito de se manifestar, completamente reconhecido pelo Estado e pela grande mídia que acompanhava as manifestações. De forma distinta, o Estado não podia reconhecer aquele que não o reconhecia como autoridade, porque esse é um dos princípios primordiais de sua própria existência. Aquele que teoricamente detém o monopólio da violência não pode reconhecer, pelo menos pública e legitimamente, a violência fora dele.

De que forma deve-se pensar em uma luta por reconhecimento que parta da luta para reconhecer a existência de um grupo que não aceita não poder deixar de aceitar?

Isso pode ser tanto uma manifestação anarquista ou um momento revolucionário ou até mesmo uma ação criminal. Athanasiou avança nessa perspectiva:

Eu concordo que reconhecimento tem de ser ele mesmo transformador, autodesconstrutor, força. Também penso que essa questão viabiliza um espaço de trabalho para a esquerda política e os movimentos sociais nas nossas condições contemporâneas, os quais necessitam considerar como somar reconhecimento sem perpetuar e intensificar os termos estabelecidos de reconhecença que eles buscam opor (Butler \& Athanasiou, 2013: 88). 
Em síntese, a perspectiva de Butler acrescida das intervenções de Athanasiou são especialmente importantes de serem consideradas quando o fenômeno a ser analisado é caracterizado pela dispersão. A busca de sentido, nesse caso, pode ser o não sentido coletivo, a não presença da política.

\section{À guisa de conclusão}

Seria possível criticar este artigo pelo fato de comparar propostas teóricas não comparáveis. Que o reconhecimento de que falam Fraser e Honneth não parte das mesmas premissas epistemológicas de Butler. A crítica é sempre possível, mas a defesa também o é. Há um princípio articulador nesses três autores que permite tal comparação: todos estão preocupados com a superação das atuais formas de dominação, todos estão focados em sujeitos contemporâneos e em crise, todos os três têm a luta pelo reconhecimento como central na superação (ou desconstrução) do modo capitalista de dominação.

O propósito de usar esses três autores foi o de buscar ferramentas para analisar um evento que não foi, nem no Brasil, nem em suas variantes no resto do mundo, voltado sempre para a libertação, a justiça, a igualdade, a paridade. Porém, no caso do Brasil (e penso que provavelmente em muitos outros países), a questão do reconhecimento foi muito articuladora, mas nem sempre de posturas de luta, de conteúdo, de reconhecimento de identidades equivalentes. E, nesse sentido, os três autores estudados têm contribuições para se refletir sobre esse novo tipo de ação pública. Há um crescendo de possibilidades de análise a partir deles, que começa timidamente com Fraser, tem mais protagonismo com Honneth e chega aos textos inquiridores de Butler, que, na minha hipótese, é a que melhor pode instrumentalizar a análise a partir da noção de reconhecimento.

À guisa de conclusão, gostaria de recuperar os principais pontos discutidos ao longo do texto, tendo como referência básica as manifestações de junho de 2013 no Brasil. Esses eventos foram muito particulares porque não caracterizaram uma ideologia, uma luta específica, um tipo de categoria profissional, nem mesmo um objetivo. Apareceram como grandes manifestações públicas convocadas primordialmente pelas redes sociais e desapareceram deixando como herança a força que mostraram parando cidades: o que foi recuperado com frequência por grupos organizados, sindicatos, trabalhadores em luta com os sindicatos, moradores descontentes com as condições das ruas de seus bairros, o movimento dos sem teto, os usuários do transporte público etc. Estes todos são sujeitos organizados com pautas claras. Durante o Junho de 2013 havia apenas uma luta comum: os manifestantes queriam ser reconhecidos como não políticos, como diferentes dos políticos. Eram apenas 
indivíduos e insistiam muito nessa condição. Fraser deixa fora de sua análise os não organizados, que não têm senso político. Por isso, sua teoria dualista pode explicar as lutas específicas que aconteceram dentro das manifestações, mas deixa pairando no ar a grande maioria que foi para as ruas. Honneth, por outro lado, com sua percepção do autorreconhecimento e das três esferas de luta por reconhecimento, dá guarida aos deixados de fora por Fraser. Não é difícil identificar nos manifestantes a busca por reconhecimento legal (contra a corrupção; por melhores serviços públicos etc.) e até por estima, quando médicos, por exemplo, se sentiram desrespeitados pelo governo federal com a instituição do Programa Mais Médicos, para suprir a falta desses profissionais em diversas partes do país no atendimento à população.

No entanto, os dois teóricos têm o télos da libertação em suas teses. O crítico de Honneth - Veit Bader - aponta com muita clareza para a dificuldade de aceitar todas as queixas de falso reconhecimento como justas. Isso é particularmente interessante quando percebemos que, nas manifestações de junho de 2013, enquanto um pedia mais segurança, outro saqueava lojas e quebrava portas de bancos. Enquanto a maioria se dizia contra a política, grupos organizados lutavam por democracia direta. Enquanto uns se enrolavam na bandeira nacional e cantavam o hino, outros declaravam-se anarquistas. Quando a grande maioria dizia "eles não nos representam", essas pessoas não estavam pedindo por reformas para que fossem mais representados. Há luta por reconhecimento nessas manifestações? Diria que sim, e mais, diria que não há nada além de uma luta por reconhecimento de indivíduos fragmentados, individualizados e sem uma perspectiva política única, ou melhor, sem objetivos políticos. Lutaram por serem reconhecidos como sujeitos fora do campo político, como a negação do campo, fossem eles de que coloração política fosse.

As manifestações de junho de 2013 resultaram em um momento aparentemente contraditório: as massas se moviam pelas avenidas das grandes cidades, porém sem construírem um sentido de coletivo, um ou mais objetivos que unissem os indivíduos, conquistas pelas quais lutar, inimigo comum contra o qual se unir. Foi o domínio da fragmentação. Os grupos minoritários organizados foram praticamente expulsos das ruas, ou por temer serem confundidos com seus contrários, como foi o caso do MPL, ou pela revolta dos apartidários, caso dos militantes de partidos. Restou à massa a luta por ser reconhecida como não política, não partidária.

Quais as consequências dessas manifestações pensando a partir da perspectiva de lutas por reconhecimento? As possibilidades estão abertas, três parecem mais prováveis: a continuidade da dispersão e a confluência de demandas legítimas e ilegítimas por reconhecimento; a possibilidade de lutas por reconhecimento a partir de coalizões abertas mais ou menos estruturadas conforme o momento na perspectiva 
trabalhada por Butler; a continuidade e mesmo o reforço de grupo organizados, já reconhecidos como tal, como diria Honneth, que tiveram grande visibilidade durante os eventos. Nada, entretanto, indica que o Junho de 2013 tinha potencial para provocar mudanças a partir da mobilização de sujeitos que buscavam uma nova forma de pacto social ou político ou econômico. Para isso, a luta por reconhecimento teria de ser outra.

Finalmente, de 2014 a 2016, houve muitas manifestações de rua, que reuniram milhões de pessoas e onde grupos organizados através de redes sociais chamaram as pessoas com demandas específicas e politizadas. Este artigo não analisou estes eventos, mas quer pontuar que a fragmentação identificada em 2013 foi fundamental como matéria-prima para o que aconteceu nos anos seguintes.

Abstract: This article aims to discuss the theories of recognition as instruments for analysis of street demonstrations that took place in Brazil in June 2013. It examines three authors: Nancy Fraser, Axel Honneth and Judith Butler, describing the central points of the theory of recognition of each one of them, in order to point out the possibilities and limits of its application in the study at hand. The hypothesis that guides the article is as follows: in the 2013 street demonstrations, the absence of organized collective subjects featured a dispersion and fragmentation condition, resulting in a demand for anti-political and individual recognition. Given this scenario, the article concludes that Judith Butler's theses on recognition were the ones that were more appropriate to the analysis of events.

Keywords: social theory, theories of recognition, poststructuralim, Nancy Fraser, Axel Honneth, Judith Butler, Street demonstrations in Brazil in July 2013.

\section{Referências}

ALTHUSSER, Louis. Lenin and philosophy. London: New Left Review Editions, 1971.

BADER, Veit. Misrecognition, power, and democracy. In: BRINK; Bert van den; OWEN, David. Recognition and power. Axel Honneth and the tradition of critical social theory. New York: Cambridge University Press, 2007.

BUTLER, Judith. Problemas de gênero. Rio de Janeiro: Civilização Brasileira, 2012.

- Speaking up, talking back: Joan Scott's critical feminism. In: BUTLER, Judith; WEED, Elizabeth (Eds.). The question of gender, Joan W Scott's critical feminism. Bloomington: Indiana University Press, 2011.

_. Precarious life. London: Verso, 2004. 
BUTLER, Judith; ATHANASIOU, Athena. Dispossession: the performative in the political. Cambridge: Polity Press, 2013.

CASTELLS, Manuel. Networks of outrage and hope. London: Polity Press, 2012.

CARTA CAPITAL. n. 760, p. 36, 5 Ago. 2013. Entrevista sobre Black Blocs.

COHEN, Jean; ARATO, Andrews. Civil society and the political theory. Cambridge: MIT Press, 1994.

COSTA, Sergio. As cores de Ercília. Belo horizonte: Editora UFMG, 2002.

DAGNINO, Evelina (Org.). Sociedade civil e espaços públicos no Brasil. São Paulo: Paz e Terra, 2002.

FRASER, Nancy. Justice interruptus: critical reflections on the "postsocialist" condition. New York: Routledge, 1997.

FRASER, Nancy; HONNETH, Axel. Redistribution or recognition? London: Verso, 2003.

GARRETT, Paul Michael. Recognizing the limitations of the political theory of recognition: Axel Honneth, Nancy Fraser and social work. British Journal of Social Work, v. 40, n. 5, p.1517-1533, 2010.

GOHN, Maria da Gloria. Novas teorias dos movimentos socais. São Paulo: Loyola, 2008.

— Teoria dos movimentos sociais. São Paulo: Loyola, 1997.

GRUESO, Delfín Ignacio. Teoría crítica, justicia y metafilosofía: la validación de la filosofía política en Nancy Fraser y Axel Honneth. Eidos - Revista de Filosofía, n. 162, 2012.

IBAÑEZ, Franklin. Nancy Fraser: escalas de justicia. Areté - Revista de Filosofía, v. 22, n. 2, p. 303-310, 2010.

LACLAU, E.; MOUFFE, Chantal. Hegemony and socialist strategy. London: Verso, 1985.

MATOS, Patrícia. O reconhecimento, entre a justiça e a identidade. Lua Nova, n. 63, p. 143-161, 2004.

MELO, Marcos; PEREIRA, Carlos. Making Brazil work checking the president in a multipary system. New York: Palgrave Macmillan, 2013.

MELUCCl, Alberto. A invenção do presente. Petrópolis: Vozes, 2001. 
MENDONÇA, Ricardo Fabrino. Democracia e desigualdade - as contribuições à teoria do reconhecimento. Revista Brasileira de Ciência Política, n. 9, p. 119-146, 2012.

- Recognition and social esteem: a case study of the struggles of people affected by leprosy. Political Studies, v. 59, n. 4, p. 940-958, 2011 a.

Reconhecimento e (qual?) deliberação. Opinião Pública, v. 17, n. 1, p. 206227, 2011b.

PINTO, Céli Regina Jardim. Nota sobre a controvérsia Fraser-Honneth informada pelo cenário brasileiro. Lua Nova, n. 74, p. 35-93, 2008.

SCHERER-WARREN, Ilse. Redes de movimentos sociais. Carta Capital, n. 760, p. 36, 5 Ago. 2013.

SWANSON, Jacinta. Recognition and redistribution rethinking culture and the economic. Theory, Culture \& Society, v. 22, n. 4, p. 87-118, 2005.

YOUNG, Iris. A critique of the ideal of universal citizenship. Ethics, v. 99, n. 2, p. 250274, 1989.

ZURN, Christopher. Identity or status? Struggles over "recognition" in Fraser, Honneth, and Taylor. Constellations, v. 10, n. 4, p. 519-537, 2003. 